\title{
T-bar Universal Rolling and Its Deformation Properties
}

\author{
Yukio TAKASHIMA and Toshiki HIRUTA \\ Steel Research Laboratory, JFE Steel Corporation, Kawasakidori 1, Mizushima, Kurashiki, 712-8511 Japan. E-mail: y-takashima \\ @jfe-steel.co.jp, t-hiruta@jfe-steel.co.jp
}

(Received on November 30, 2011; accepted on February 24, 2012)

\begin{abstract}
A new method of rolling T-bars using a common universal mill for $\mathrm{H}$-beams was investigated. To study its deformation properties, model rolling experiments and finite element analyses were carried out. Before the experiment, there was concern about large side camber of the rolled T-bars due to the asymmetric section shape in universal rolling. However, it was shown that the side camber could be controlled by adjusting the balance of the web and flange thickness reductions. The spreading behavior of the flange and web were then studied in detail by experiments and numerical simulations. Linear relationships between reduction balance and spread parameters were found, enabling the spread deformation to be predicted by using model equations. Moreover, the similarity of the flange spread behavior between T-bar and $\mathrm{H}$-beam universal rolling was investigated by numerical analysis. The result of this research suggested the high potential of this rolling method for flexible T-bar production.
\end{abstract}

KEY WORDS: section rolling; model experiment; finite element analysis; camber; flange spread.

\section{Introduction}

The section of a T-bar has two rectangles at right angles to each other. The web (or stem) is normally placed on the center of the flange.

There are several rolling methods for producing T-bars using structural mills. For example, hot rolling with groove rolls has been used for many years, and several roll pass designs for T-bars have been presented in the literature. ${ }^{1-3)}$ However, the products produced by groove rolling have a taper in their web and flange thicknesses, which is a drawback of this rolling method.

Three roll mills are sometimes applied to T-bar production $^{4-6)}$ to produce T-bars having a web and flange of uniform thickness. However, three roll mills are normally used for only small sections.

Another method of producing T-bars is to slit of $\mathrm{H}$ beams. ${ }^{1-3,7)}$ Because of the constant thickness of $\mathrm{H}$-beams, slit T-bars have no taper in their web and flange thicknesses, and thus a great many T-bars are now being produced in this way.

Recently, the use of T-bars in shipbuilding is increasing, ${ }^{7-9)}$ but the dimensions of hot rolled and slit T-bars are not suitable, T-bars having a web height at least twice the flange width are generally required for shipbuilding. According to a report, ${ }^{8)}$ the $\mathrm{T}$ bar requires a web inner height of 9.25 inches and flange width of 3.25 inches $(9.25 \times 3.25)$. Other Tbar sizes of $481 \times 150$ and $700 \times 200$ were proposed for the bottom longitudinal sections of a tanker. ${ }^{9)}$

On the other hand, the ratio of the web height to flange width of hot rolled and slit T-bars is less than two. Although universal rolling technology for slimmer H-beams suitable for producing T-bars for ship building is being investigated, ${ }^{10}$ ) actual production of this H-beam is still under consideration. As a result, T-bars for ships are typically fabricated by weld- ing two plates. ${ }^{7,8)}$

Another disadvantage of hot rolled T-bars in shipbuilding is their size availability. In the case of fabricated T-bars, the widths and thicknesses of the web and flange can be selected flexibly from plates of various thicknesses. On the contrary, the variations in size of hot rolled or slit T-bars are rather limited. When section sizes are limited, a thicker section having more than the required stiffness should be selected, but this means the increases the ship weight. ${ }^{7,8)}$ In the case of groove rolling, a roll pass design can produce only one section, which means that many sets of groove rolls are necessary for supplying various sizes of T-bars. The mismatch of outer dimensions and lack of size variations are problems of hot rolled T-bars in shipbuilding.

To solve these problems, a new rolling method for T-bars was investigated in this study. The possibility of T-bar rolling with a conventional universal mill was studied by model rolling experiments. Basic deformation properties were also investigated from the results of model experiments and finite element (FE) simulation, particularly the behaviors of the flange and web spreads. Furthermore, the flange spread behavior of T-bar rolling was compared to that of H-beam rolling, and their similarities and differences were discussed.

\section{Fundamentals of T-bar Universal Rolling}

Universal mills are widely used for the production of $\mathrm{H}$ beams, as shown schematically in Fig. 1. A Japanese patent published in 1968 presented a unique approach for T-bar rolling, ${ }^{11)}$ applying a universal mill for $\mathrm{H}$-beam rolling to $\mathrm{T}$ bar rolling, as shown in Fig. 2. The web of the T-bar is rolled with horizontal rolls and the flange is rolled between a vertical roll and the side surfaces of the horizontal rolls. Flange width is controlled with an edger mill installed near 


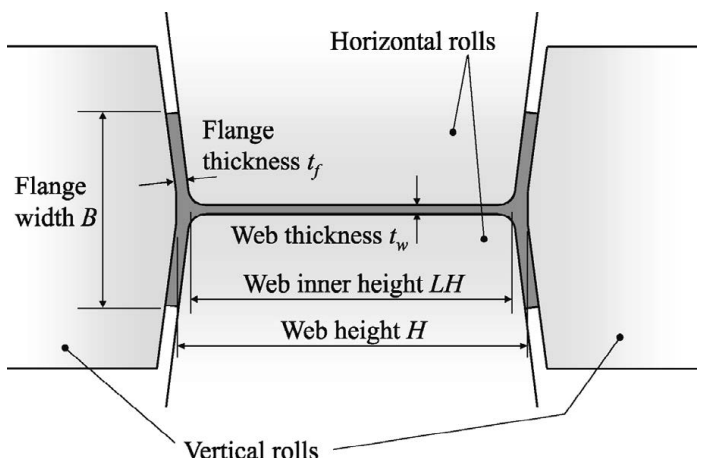

Fig. 1. Universal rolling of H-beam.

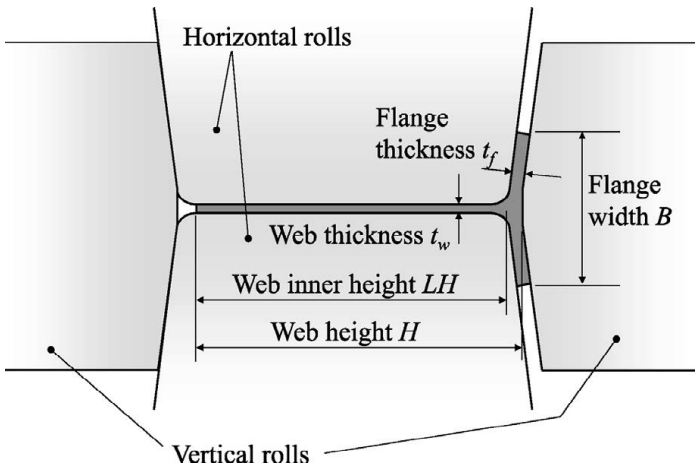

Fig. 2. Universal rolling of T-bar.

the universal mill. The edger rolls also have the same configuration as for H-beam rolling. After reducing the web and flange thicknesses to the product dimensions, another universal mill is used to make the flange shape straight and vertical.

This method offers many advantages. First, as shown in Fig. 2, slim T-bars suitable for shipbuilding can be rolled. Second, T-bars having different outer dimensions and thicknesses can be produced with the same pair of horizontal and vertical rolls, which enabling a range of product sizes to be produced without increasing the roll cost. Moreover, universal mills are commonly used for section rolling, and therefore unlike introducing a special rolling mill such as a threeroll type, it is possible for conventional section mills to produce T-bars with their existing facilities.

However, this universal rolling method has not been examined since the patent was published, probably because the asymmetric rolling shape that lacks one flange of the H-beam is expected to produce large side camber in universal rolling.

To assess the possibility of T-bar universal rolling, we carried out experimental and numerical studies simulating this rolling method. First, basic rolling deformation was studied by conducting model rolling experiments.

\section{Experimental Setup}

To investigate general rolling deformation, reduced-scale model experiments were performed. A laboratory universal mill having the same roll arrangement as shown in Fig. 2 was used. The horizontal rolls were driven and the vertical rolls were undriven. The dimensions of the rolling mill and experimental conditions are shown in Tables $\mathbf{1}$ and $\mathbf{2}$, respectively. A T-bar product with a web height of $300 \mathrm{~mm}$ and flange width of $125 \mathrm{~mm}$ was assumed. A constant
Table 1. Dimensions of laboratory universal mill.

\begin{tabular}{l|l|c}
\hline \multirow{2}{*}{ Roll diameter $(\mathrm{mm})$} & Horizontal roll & 180 \\
\cline { 2 - 3 } & Vertical roll & 140 \\
\hline Horizontal roll rotation speed & $7 \mathrm{rpm}$ \\
\hline Flange inclination angle & $6 \mathrm{deg}$. \\
\hline
\end{tabular}

Table 2. Experimental conditions.

\begin{tabular}{l|l|c|c}
\hline \multirow{2}{*}{ Model scale } & \multicolumn{2}{|c}{$1 / 5$} \\
\hline \multicolumn{1}{l}{ Model material } & \multicolumn{2}{|c}{ Pure lead $(99.99 \%)$} \\
\hline \multicolumn{1}{l}{ Conditions of inlet section } & Thick section & Thin section \\
\hline \multirow{3}{*}{$\begin{array}{l}\text { Inlet material } \\
\text { size }(\mathrm{mm})\end{array}$} & Web height, $H$ & 61 & 60 \\
\cline { 2 - 4 } & Flange width, $B$ & 26 & 23 \\
\cline { 2 - 4 } & Web thickness, $t_{w}$ & 4.0 & 2.0 \\
\cline { 2 - 4 } & Flange thickness, $t_{f}$ & 8.0 & 4.0 \\
\hline \multirow{2}{*}{$\begin{array}{l}\text { Target thickness } \\
\text { reduction }\end{array}$} & Web, $r_{w}$ & $r_{w}=15 \%, r_{f}=12,18,24 \%$ \\
\cline { 2 - 4 } & Flange, $r_{f}$ & $r_{w}=21 \%, r_{f}=18,24,27 \%$ \\
\hline
\end{tabular}

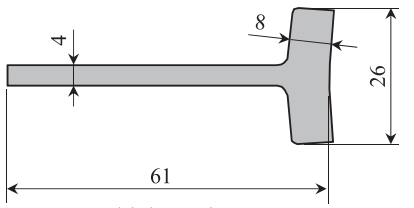

Thick section

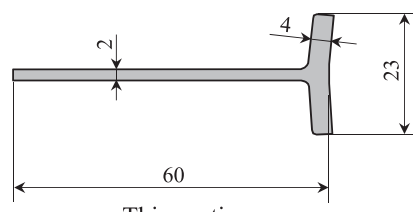

Thin section
Fig. 3. Inlet sections of the rolling experiments.

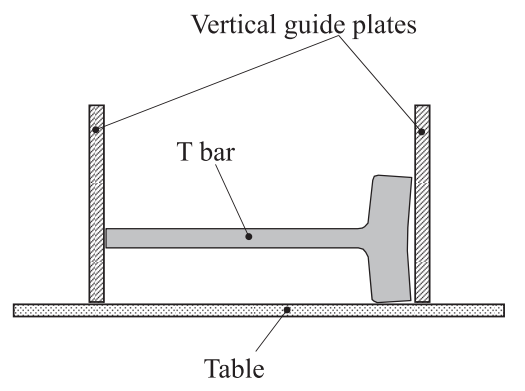

Fig. 4. Layout of vertical guide plates.

reduced-scale of one fifth was assumed in the experimental rolling. Pure lead was used as the model material of the Tbar, which is reported to have deformation behavior similar to that of hot carbon steel at elevated temperatures from 900 to $1000^{\circ} \mathrm{C}^{12)}$ Because these experiments were carried out at room temperature, the effect of temperature distribution on rolling deformation was eliminated.

Two inlet sections as illustrated in Fig. 3 were examined. The thick section $\left(t_{w 0}=4 \mathrm{~mm}\right)$ corresponded to an early pass in the draft schedule of universal rolling, and the thin section $\left(t_{w 0}=2 \mathrm{~mm}\right)$ matched the end of the draft schedule. Several combinations of web thickness reduction $r_{w}$ and flange thickness reduction $r_{f}$, as listed in Table 2, were tested. The range of thickness reduction difference $\left(r_{f}-r_{w}\right)$ was from $-3 \%$ to $9 \%$. Two specimens were rolled for each condition. In total, twelve T-bar stocks were examined for each inlet section.

As shown in Fig. 4, vertical guide plates were placed on the both sides of the T-bar to prevent side camber of the T- 
bar. Two pairs of vertical guides were applied to the entry and exit sides of the laboratory universal mill.

\section{Influence of Rolling Conditions on Side Camber}

The types of side camber are illustrated in Fig. 5. When $r_{w}$ was larger than $r_{f}$, camber occurred on the flange side. On the other hand, when $r_{f}$ was much larger than $r_{w}$, camber occurred on the web side. The cambers were observed at the top end of the rolled T-bar and did not appear after the contact with the vertical guides. When $r_{f}$ exceeded $r_{w}$ by a few percent, the rolled T-bar was almost straight.

In the rolling experiments, all workpieces were rolled without serious problems. However, in the case of thin inlet section, web edge waving occurred when $r_{w}$ was larger than $r_{f}$. When $\left(r_{f}-r_{w}\right)$ was the same, larger thickness reduction caused more obvious edge waving.

The edge waving occurred under the conditions of flange side camber. It is presumed that the correction of flange side camber by the vertical side guides caused compressive stress on the web edge, resulting in edge waving in the thin inlet T-bars. On the contrary, edge waving was not observed under the conditions of web side camber. Except for the waving defect, all rolled T-bars kept good shapes. Contrary to the side camber, upward and downward curling of the rolled T-bar was small and negligible.

The results of this experiment showed that the camber of rolled T-bars can be minimized by adjusting the web and flange thickness reductions. At the same time, the web edge waving can be avoided by appropriately setting the same thickness reductions.

\section{Modeling and Investigation of Spread Deformations}

In H-beam universal rolling, the spread of flange width $B$ has been studied in detail, ${ }^{13,14)}$ and it has been shown that the difference between flange and web thickness strain strongly influences flange spread. A similar influence was expected in T-bar universal rolling. Flange spread behavior in H-beam universal rolling is expressed by the following equation: ${ }^{13,14)}$

$$
\ln \left(B_{1} / B_{0}\right)=a \cdot\left(\lambda_{f}-\lambda_{w}\right)+b
$$

where $\lambda_{w}$ and $\lambda_{f}$ are the thickness strains of the web and flange, and are calculated using the following equations:

$$
\begin{gathered}
\lambda_{w}=\ln \left(t_{w 0} / t_{w 1}\right) \\
\lambda_{f}=\ln \left(t_{f 0} / t_{f 1}\right)
\end{gathered}
$$

where $t_{w}$ and $t_{f}$ are the thicknesses of the web and flange. The suffixes 0 and 1 mean before and after rolling, respec-

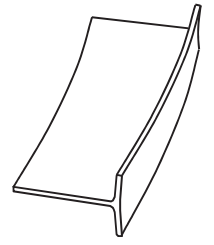

Web side camber

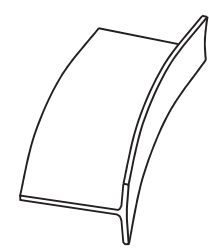

Flange side camber
Fig. 5. Types of side cambers in T-bar universal rolling. tively. In Eq. (1), $a$ and $b$ are constants depending on the Hbeam dimensions and rolling mill geometry. The difference between the flange and web thickness strain $\left(\lambda_{f}-\lambda_{w}\right)$ is considered to be the representative parameter of the correlation between the web and flange and is called "reduction balance" in this paper.

In H-beam universal rolling, flange tips are free surfaces, and thus flange spread is the representative parameter of rolling deformation. In the case of T-bar rolling, the tip of the web is also a free surface. Because of this situation of T-bar universal rolling, both spreads of flange width $B$ and web inner height $L H$ were investigated in this research. The change of web inner height was evaluated by calculating $\ln \left(L H_{1} / L H_{0}\right)$ as the same type of deformation parameter with the flange spread.

The thickness reductions in Table 2 were target values; the actual thickness reductions might be different from the targets. The actual dimensions of the T-bar before and after rolling were measured at the center of the length, and these measurements were used to calculate the actual thickness strains and spread deformation parameters.

Figures 6 and 7 show the relationships between the reduction balance and the spread parameters for thick and thin inlet size conditions, respectively. In both inlet sections, linear relationships between the flange and web spread parameters and reduction balance can be seen. Similar to $\mathrm{H}-$ beam rolling, a larger reduction balance causes a larger flange spread. The spread of web inner height shows the opposite trend, with rather shallow inclinations of regression lines. These results demonstrated that the spread deforma-

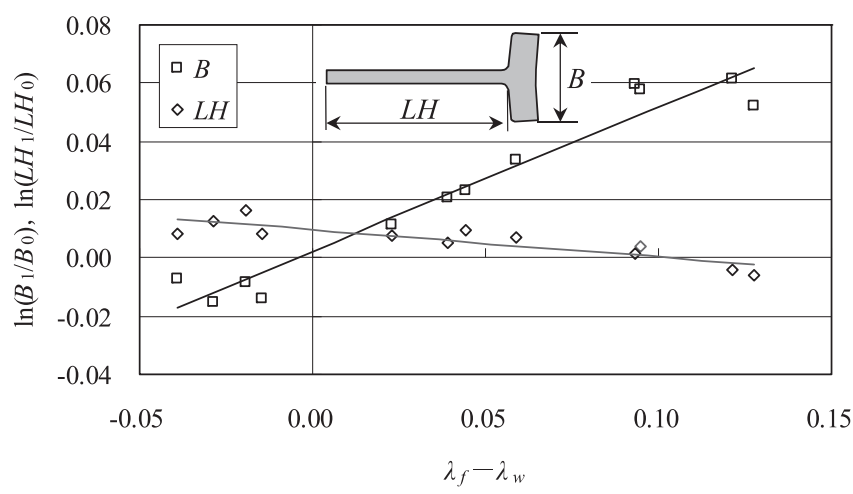

Fig. 6. Influence of reduction balance on flange and web spread (experiment, thick section).

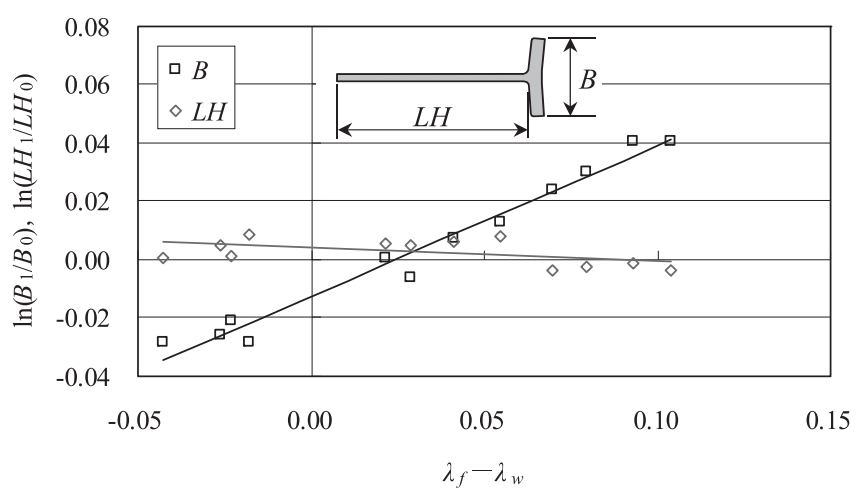

Fig. 7. Influence of reduction balance on flange and web spread (experiment, thin section). 
tion in T-bar universal rolling can be expressed using the flange spread model of the H-beam in Eq. (1).

With regard to the influence of the inlet thickness, the spreads of the thick section were a little larger than those of the thin section. The effect of web reduction $(15 \%$ or $21 \%)$ on spread deformation is unclear and seems very small.

The model experiments clearly demonstrated the possibility of this T-bar rolling method, and also clarified that the model equation of $\mathrm{H}$-beam rolling is applicable to T-bar universal rolling.

However, the experimental data have some range of scatter that makes the trend somewhat unclear. To clarify the deformation behavior, FE analysis was carried out under the same conditions as the experiments.

\section{Finite Element Modeling of T-bar Universal Rolling}

To study the deformation properties in T-bar universal rolling in detail, highly accurate numerical analysis is required, and so a Lagrange multiplier three-dimensional rigid-plastic FE analysis, the CORMILL System, ${ }^{15)}$ was selected. Many rolling passes of various sections including H-beam universal rolling have been analyzed successfully with this simulation system. ${ }^{14,15)}$ Its implicit calculation method can provide highly accurate results for deformation, stress and strain.

In the CORMILL System, plastic deformation is simulated in a steady state model. When investigating fundamental deformation properties, steady state analysis is suitable for obtaining adequate information with less computational load.

Because a T-bar has a symmetrical section shape, a half T-bar was modeled for the analysis. The rolls were assumed to be rigid bodies. The undriven condition of the vertical rolls was considered by adjusting the rotation speed to minimize the roll torque calculated in the iteration.

Actual rolling geometries corresponding to the model rolling experiments were used in the numerical simulation. Corresponding to the experiment, the simulated product had a web height of $300 \mathrm{~mm}$ and flange width of $125 \mathrm{~mm}$. Two inlet sections having different thicknesses were also modeled for the numerical simulation. The dimensions of the rolls and stocks are listed in Table 3.

Table 3. Numerical conditions.

\begin{tabular}{|c|c|c|c|}
\hline \multicolumn{2}{|c|}{ Condition of inlet section } & Thick section & Thin section \\
\hline \multicolumn{2}{|c|}{ Product size of T-bar } & \multicolumn{2}{|c|}{$300 \times 125$} \\
\hline \multirow{4}{*}{$\begin{array}{l}\text { Inlet material } \\
\text { size }(\mathrm{mm})\end{array}$} & Web height, $H$ & 330 & 310 \\
\hline & Flange width, $B$ & 136 & 126 \\
\hline & Web thickness, $t_{w}$ & 20 & 10 \\
\hline & Flange thickness, $t_{f}$ & 40 & 20 \\
\hline \multirow{2}{*}{$\begin{array}{l}\text { Roll diameter } \\
(\mathrm{mm})\end{array}$} & Horizontal roll & \multicolumn{2}{|c|}{900} \\
\hline & Vertical roll & \multicolumn{2}{|c|}{700} \\
\hline \multicolumn{2}{|c|}{ Horizontal roll rotation speed } & \multicolumn{2}{|c|}{$10 \mathrm{radian} / \mathrm{sec}$} \\
\hline \multicolumn{2}{|c|}{ Flange inclination angle } & \multicolumn{2}{|c|}{$6 \mathrm{deg}}$. \\
\hline \multirow{2}{*}{$\begin{array}{l}\text { Target thickness } \\
\text { reduction }\end{array}$} & Web, $r_{w}$ & \multicolumn{2}{|c|}{$r_{w}=15 \%, r_{f}=12,15,18,21,24 \%$} \\
\hline & Flange, $r_{f}$ & \multicolumn{2}{|c|}{$r_{w}=21 \%, r_{f}=18,21,24,27,30 \%$} \\
\hline \multicolumn{2}{|c|}{ Friction coefficient } & \multicolumn{2}{|c|}{0.3} \\
\hline
\end{tabular}

In our previous research on H-beam universal rolling, suitable element numbers were investigated by careful numerical trials. ${ }^{14)}$ The same element numbers employed in the research were used in the FE simulation: the element number was six and thirty in the thickness and width directions, respectively. The element shapes in the thick section are illustrated in Fig. 8. The element number in the rolling direction was determined to be 28 in total from the entry section to the exit section. The boundary conditions of the steady state analysis were similar to those in other researches. ${ }^{14,15)}$ Uniform velocities throughout the cross sections of the entry and exit boundaries were assumed; this boundary condition restricts the camber of the rolled T-bar and makes the numerical condition closer to the rolling experiments.

\section{Numerical Conditions}

In the T-bar universal rolling experiments, six combinations of web and flange thickness reductions were examined, whereas ten combinations were executed in the FE simulation. As shown in Table 3, two web thickness reductions, $15 \%$ and $21 \%$, were selected again. Five flange reductions for each web reduction were simulated.

A flow stress curve for hot carbon stee ${ }^{16)}$ was applied to the analysis with a minor modification as follows:

$$
\sigma_{f}=113.2 \cdot(0.02+\varepsilon)^{0.21} \cdot \dot{\varepsilon}^{0.13}
$$

where $\sigma_{f}$ is flow stress in $\mathrm{MPa}, \varepsilon$ is plastic strain and $\dot{\varepsilon}$ is plastic strain rate. The constant 0.02 was added to the original flow stress equation to avoid calculating abnormally small flow stress in the pre-deformation part in the FE model. A constant rolling temperature of $1000^{\circ} \mathrm{C}$ was assumed in the stock. The value 113.2 was calculated from the stock temperature $T$ in Kelvin as $\exp \left(K^{\prime}+A / T\right)$. The values of $K^{\prime}$ and $A$ were determined from the percentage of carbon content, which was set to $0.15 \%$ in the FE simulation.

Coulomb friction was assumed between rolls and materials, and a friction coefficient of 0.3 was used for all FE analyses.

\section{Results of Numerical Simulation}

Numerical simulations for all rolling conditions in Table 3 were carried out successfully. The target thickness reductions in Table 3 mean the setting of the roll gaps. The simulated thickness after rolling may differ from the roll gaps because of thickness changes after rolling. ${ }^{14)}$ To compare the results of FE analysis (FEA) with the experimental data (EXP), the thicknesses at the final exit section were used for calculating the reduction balance.

The relationships between reduction balance and spread parameters are shown in Figs. 9 and 10. The trends of each inlet size are similar to the experimental results shown in Figs. 7 and 8, and the range of scatter is smaller than in the

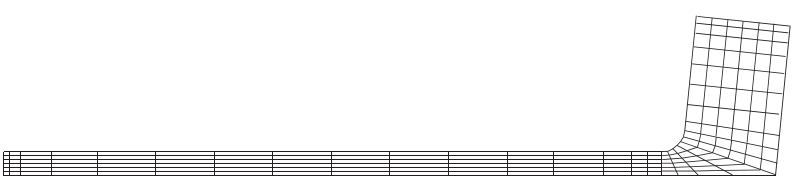

Fig. 8. Elements in the section (thick section). 


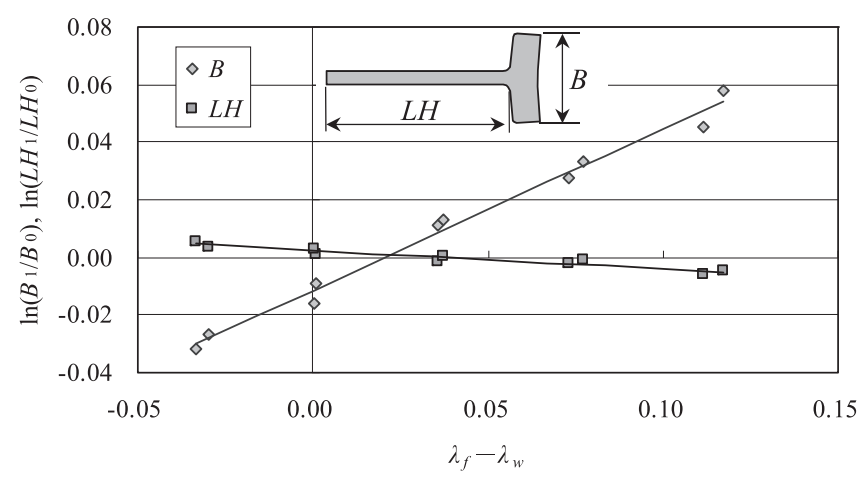

Fig. 9. Influence of reduction balance on flange and web spread (FE analysis, thick section)

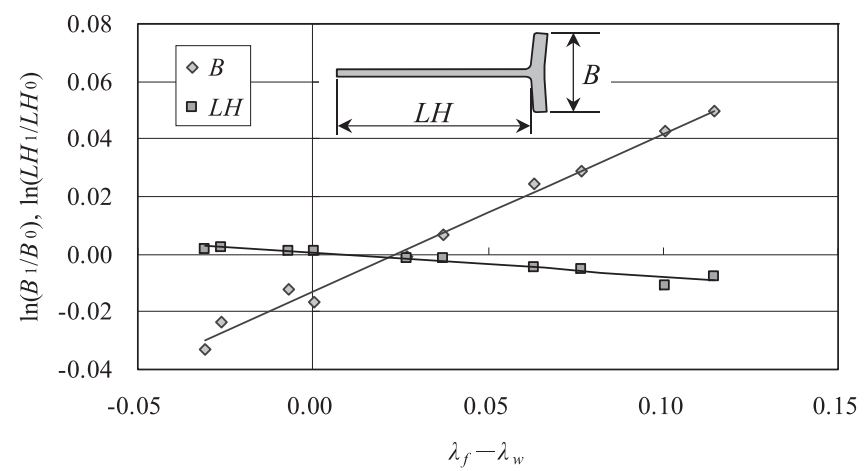

Fig. 10. Influence of reduction balance on flange and web spread (FE analysis, thin section).

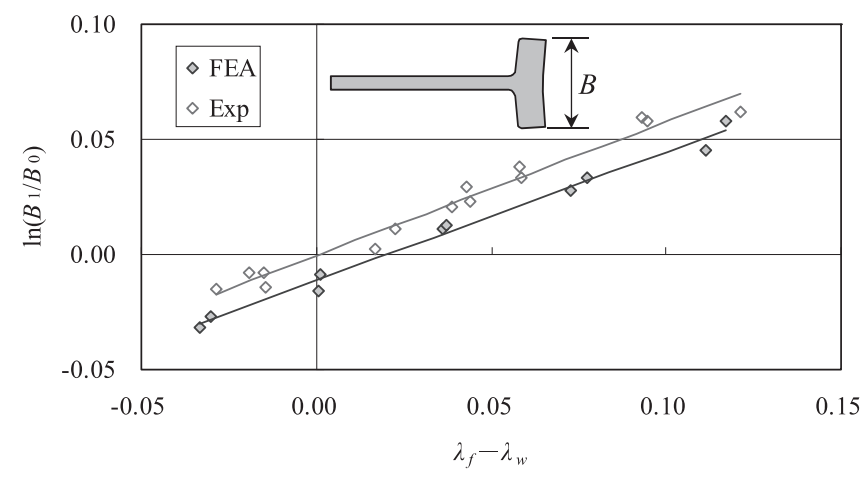

Fig. 11. Comparison of flange spread behavior between FE analysis and experiment (thick section).

experiment, thus clarifying the relationship between spread parameters and reduction balance. The results of the thick and thin sections are almost the same, and the influence of the web thickness reduction is negligibly small.

The experimental and numerical results of the flange and web spread in the thick condition are compared in Figs. 11 and 12, showing similar inclinations of regression lines between the experimental and numerical results. The intercepts of the line obtained from the experiments are about 0.01 larger than those of the FE simulations, probably due to the shape of the free surface. The flange tip of the experimental stocks had a slightly bulging shape, whereas it was assumed to be a straight line in the FE analysis. It was confirmed that the difference of the flange tip shape influences the amount of spread parameter. FE analysis with a bulging inlet flange tip was carried out, and the results showed a larger intercept than that of the straight flange tip. Consid-

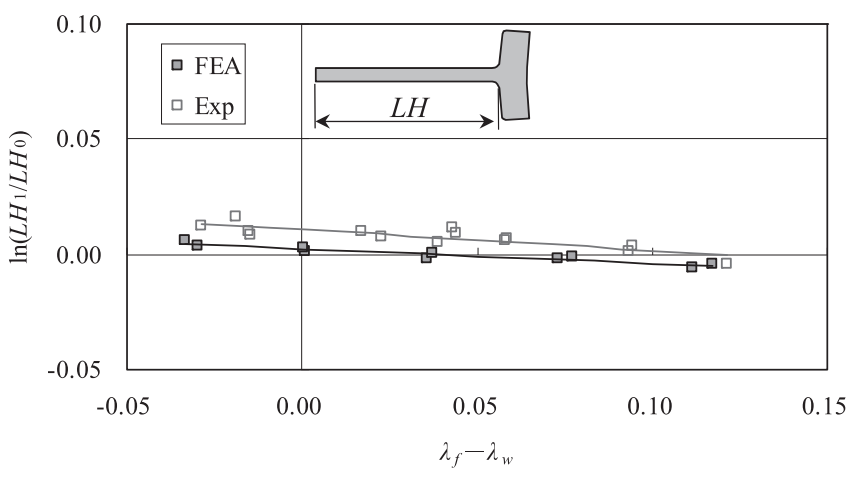

Fig. 12. Comparison of web spread behavior between FE analysis and experiment (thick section).

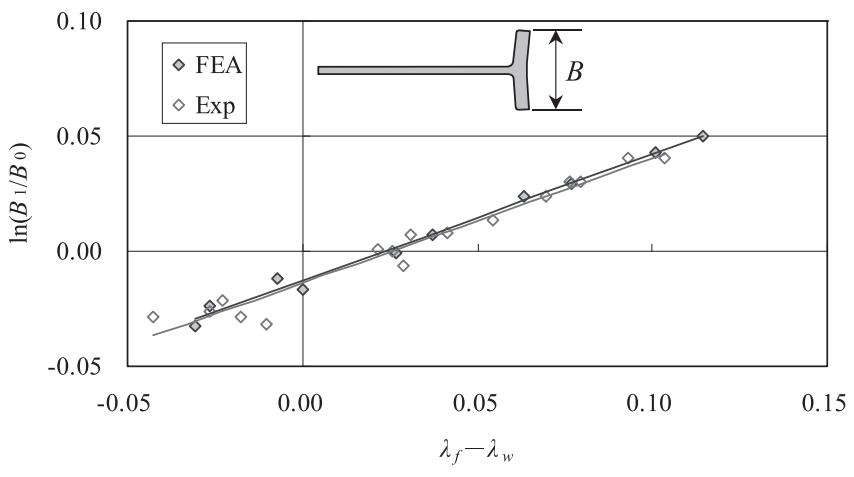

Fig. 13. Comparison of flange spread behavior between FE analysis and experiment (thin section).

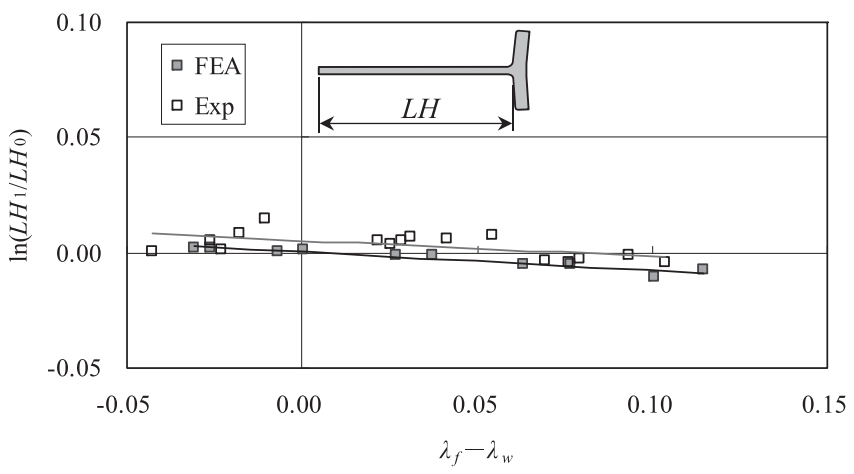

Fig. 14. Comparison of web spread behavior between FE analysis and experiment (thin section).

ering the small difference of the initial free surface shape, the results of FE simulation agree well with the experimental results.

Figures 13 and 14 compare the experimental and numerical analysis results for the thin section; both the flange and web spread show excellent agreement.

The comparison between experimental and numerical results confirmed the excellent accuracy of the FE simulation. It was also clarified that the flange and web spread can be predicted by using reduction balance in the form of Eq. (1). This simple prediction of rolling deformation is very useful for optimizing the conditions of T-bar universal rolling.

Although cambers were restricted in this FE analysis, it is possible to investigate the extent of side cambers by using the stress distribution at the exit section. ${ }^{15)}$ In the steady state modeling of the CORMILL System, the deforming 


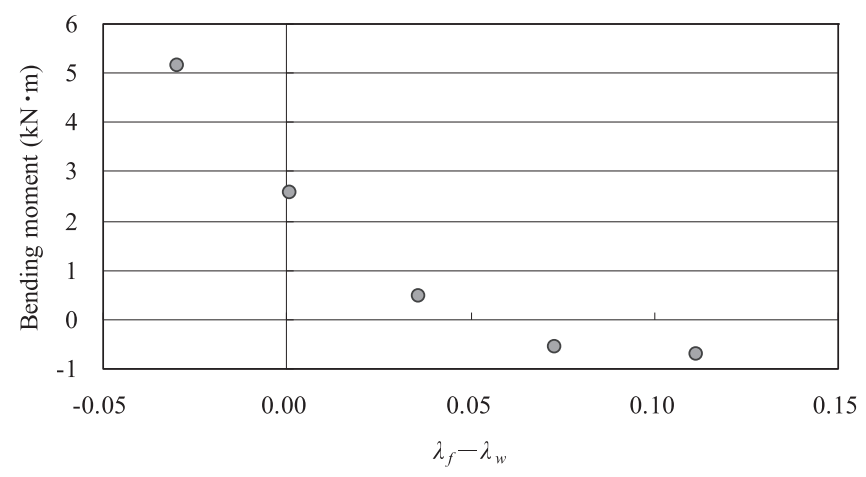

Fig. 15. Bending moments of $\mathrm{T}$-bars at the exit sections (thick section, $\left.r_{w}=15 \%\right)$.

zone is connected with non-deforming zones before entry and after exit. In order to maintain a straight product flow, uniform longitudinal velocities were assumed in the entry and exit cross-sections. These boundary conditions require bending moments at the connecting planes. The extent of side camber can be predicted by the value of the bending moment at the exit section. When the calculated moment is zero, the rolled material flows straight and the side camber becomes zero.

Using the simulated stress in the rolling direction, the bending moment at the final exit section was calculated using the results for the thick section. Figure 15 shows the calculated bending moments of the full-section T-bar in the case of a target web thickness reduction $\left(r_{w}\right)$ of $15 \%$. A positive bending moment corresponds to flange side camber. It is found that the bending moment becomes zero around a reduction balance of 0.04 , which corresponds to a $3.3 \%$ difference in the flange and web thickness reductions and closely matches the experimental results. The prediction of extent of camber with FE simulation is very useful for determining suitable rolling conditions.

\section{Flange Spread Behavior of T-bar and H-beam Roll- ing}

From the results of the model experiment and FE simulation, deformation properties of T-bar universal rolling were clarified. The flange spread of T-bar universal rolling showed similar trends to $\mathrm{H}$-beam universal rolling. Because H-beam universal rolling is widely applied to actual production, much knowledge in connection with the suitable mill settings and operation is available. If the affinity between $\mathrm{H}-$ beam and T-bar universal rolling can be clarified, knowledge regarding H-beam rolling can be transferred to T-bar universal rolling. This technology transfer will be very useful when applying the new T-bar rolling method to actual section mills. To investigate the similarity of flange spread deformation between H-beams and T-bars in detail, FE simulation of H-beam universal rolling was carried out.

In H-beam rolling, the center of the web is located in a symmetric plane. In T-bar universal rolling, web inner height showed only a small change, and so a T-bar having half the section of an H-beam is expected to show similar flange deformation property to the original H-beam. Furthermore, a slit T-bar of such H-beam has the same section as the corresponding rolled T-bar.

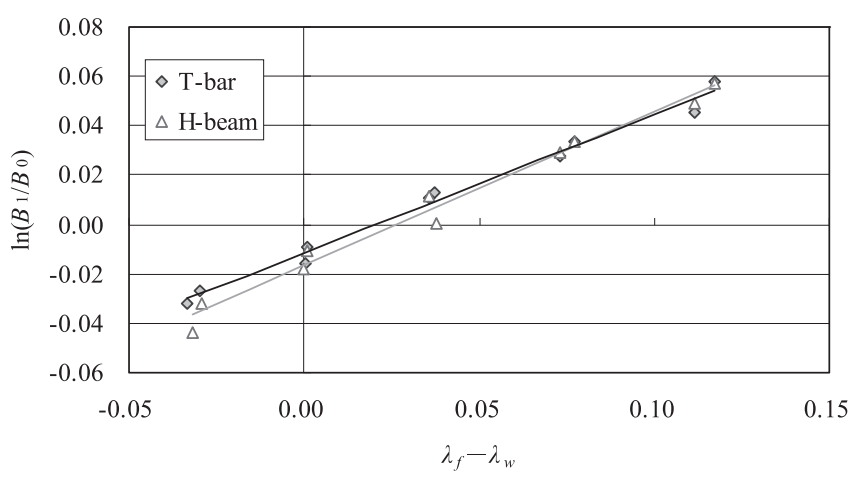

Fig. 16. Flange spread behavior of T-bar and H-beam.

Based on this assumption, H-beam universal rolling was simulated with the CORMILL System. In the simulation, the same elements of the thick inlet section shown in Fig. 8 were used as a quarter part of an H-beam. Therefore, the simulated H-beam has inlet dimensions of web height of $660 \mathrm{~mm}$ and flange width of $136 \mathrm{~mm}$. The target thickness reductions in Table 3 were also applied to the H-beam analysis. Using the simulated thicknesses and flange widths after rolling, the reduction balance and flange spread parameter $\ln \left(B_{1} / B_{0}\right)$ were calculated.

The relationship between reduction balance and the flange spread parameter of the H-beam is plotted in Fig. 16 with the corresponding result of the T-bar. Although the trends of the two different sections are very similar, the inclination of the regression line of the H-beam (0.624) is a little larger than that of the T-bar (0.560).

It is surmised that this difference is due to the discrepancy of the boundary conditions. The web edge of the T-bar in FE model corresponded to the web center of the H-beam. At the web center of the H-beam, the displacement in the horizontal direction is completely restricted, whereas the web tip of the T-bar is a free surface and can move in the horizontal direction. Displacement of the web tip can decrease the effect of correlation between the web and flange, and this makes the inclination of the T-bar regression line slightly smaller.

Although there is a slight difference in the degree of correlation between the web and flange, the similarity of T-bar flange spread behavior to that of the H-beam having the same half section was quantitatively confirmed.

\section{Conclusions}

In this paper, a new method of rolling T-bars with a common universal mill was investigated by model rolling experiments and FE analyses. The experiment results clearly showed the high potential of the rolling method, and suitable rolling conditions to prevent harmful side camber were identified.

The deformation properties of flange and web spread were also studied in detail, revealing linear relationships between reduction balance and the spread parameters. Based on the linear relationships, a suitable model equation for predicting flange and web spread was proposed. FE analysis was also shown to be a powerful tool for investigating the rolling deformation of T-bars.

A numerical simulation of $\mathrm{H}$-beam universal rolling was 
carried out to investigate the similarities and differences between $\mathrm{T}$-bar and $\mathrm{H}$-beam rolling. It was shown that a Tbar having a half section of an H-beam showed almost the same flange spread behavior as the original H-beam.

The results of this study successfully demonstrated the possibility of this novel T-bar universal rolling method. Flexible production of T-bars by universal rolling would have a great impact in many industrial fields.

\section{REFERENCES}

1) R. E. Beynon: Roll Design and Mill Layout, Association of Iron \& Steel Engineers, Pittsburgh, (1956), 32, 145.

2) E. E. Brayshaw: Rolls and Rolling, Blaw-Knox Company, PA, (1958), 260.

3) R. B. Corbett: Rolls for the Metalworking Industries, Iron and Steel Society, Warrendale, PA, (1990), 84.
4) G. S. Gun, Y. P. Bogatyryov and L. E. Kandaurov: Izv. Vyssh. Uchebn. Zaved. Chern. Metall., 12 (1977), 93

5) I. Nakauchi and T. Hirasawa: Tetsu-to-Hagané, 72 (1986), S1236.

6) I. Nakauchi, T. Hirasawa, K. Morioka and Y. Suzuki: Tetsu-toHagané, 73 (1987), S1112.

7) P. A. Blomquist: J. Ship Prod., 11 (1995), 171.

8) P. A. Blomquist: J. Ship Prod., 20 (2004), 114.

9) Zosen-to-Kouzai, Kouzai-Kurabu, Tokyo, (1993), 53.

10) Y. Takashima and E. Takenouchi: Steel Res. Int., Special Edition (2011), 177.

11) Japanese Patent, Examined Publication Number 1968-19671, (1968).

12) K. Nakajima: Shape Rolling Technology of Steel, Chijin Shokan Co., Ltd., Tokyo, (1999), 213.

13) T. Misawa, K. Nakayama, K. Ototani and T. Makino: 2nd Int. Conf. Steel Rolling, Düsseldorfer Messegesellschaft $\mathrm{mbH}$, Düsseldorf, (1984), A10.

14) Y. Takashima and J. Yanagimoto: Steel Res. Int., 82 (2011), 1240.

15) J. Yanagimoto, Y. Kadomura, T. Muto and K. Inoue: Steel Res., 73 (2002), 526.

16) Y. Misaka and T. Yoshimoto: J. JSTP, 8 (1967), 414. 